\title{
Treatment strategies and outcomes in patients with non-ST- elevation acute coronary syndrome in the Netherlands
}

\author{
P. Damman · J. J. Piek
}

Published online: 14 December 2018

(C) The Author(s) 2018

Acute coronary syndrome (ACS) is predominantly caused by acute luminal narrowing due to sudden thrombus formation or plaque haemorrhage imposed on an atherosclerotic plaque [1]. A luminal thrombus forms as a direct consequence of plaque rupture or erosion. The initial electrocardiogram can be used to differentiate ST-elevation myocardial infarction (STEMI) and non-ST-elevation acute coronary syndrome (NSTE-ACS). Patients with STEMI are characterised by a complete and persistent occlusion of a large epicardial coronary artery and are best managed with immediate revascularisation by primary percutaneous coronary intervention [2]. Primary percutaneous coronary intervention (PCI) for STEMI is associated with a reduction in mortality compared with other reperfusion strategies [3].

In NSTE-ACS, typically an angiographically significant stenosis is observed while epicardial flow is maintained. Therefore, multiple treatment strategies with regard to coronary angiography and revascularisation have been investigated over the years. The first step is whether to proceed with a routine invasive or selective invasive strategy. A routine invasive strategy consists of angiography within 24 to 72 hours, while a selective invasive strategy consists of coronary angiography only in cases of refractory angina and/or inducible ischaemia by non-invasive stress testing. The Dutch multicentre ICTUS (Invasive versus Conservative Treatment in Unstable coronary Syndromes) trial

\section{P. Damman $(\bowtie)$}

Department of Cardiology, Radboud University Medical Center, Nijmegen, The Netherlands

peter.damman@radboudumc.nl

\section{J. J. Piek}

Department of Cardiology, Academic Medical Centre, Location Meibergdreef, University of Amsterdam, Amsterdam, The Netherlands has demonstrated that both treatment strategies resulted in comparable long-term death or myocardial infarction [4]. A patient-pooled meta-analysis of three trials showed that long-term rates of cardiovascular death or myocardial infarction were lower with routine invasive strategy, and that the largest absolute effect was seen in higher-risk patients [5]. The difference between the discrepant results can probably be explained by the high angiography and revascularisation rates in the ICTUS trial. Current European guidelines recommend a routine invasive strategy for patients with intermediate-to-high-risk characteristics, while the selective invasive strategy is reserved for low-risk patients [6].

The second decision involves the optimal timing of angiography after pursuing the routine invasive approach. Different timings are defined as immediate, early invasive strategy (within $24 \mathrm{hrs}$ ), or delayed invasive strategy (after $24 \mathrm{hrs}$ ). Several trials have investigated the immediate, or STEMI-like approach which was not associated with improved outcomes [7-9]. A recent meta-analysis concluded that compared with a delayed invasive strategy an early invasive strategy does not reduce mortality in all patients with NSTEACS [10]. However, an early invasive strategy might reduce mortality in high-risk patients characterised by a high Global Registry of Acute Coronary Events (GRACE) risk score (above 140). For this reason, European guidelines recommend angiography within 24 hours for high-risk patients, including transfer to a PCI centre [6]. Based on multiple considerations, including the availability of catheterisation laboratories in the majority of Dutch cardiology departments where coronary angiography is routinely performed in NSTE-ACS patients, the Dutch ACS working group does not consider referral within 24 hours as a prerequisite [11]. 
In the current issue of the Netherlands Heart Journal, Badings et al. describe the use, timing and outcome of coronary angiography in patients with high-risk NSTE-ACS in daily clinical practice in the Netherlands [12]. Consecutive ACS patients who presented at the Isala hospital in Zwolle are described. In Zwolle, consecutive patients were enrolled in the BAMI (Dutch abbreviation for 'Treatment of Acute Myocardial Ischaemia') registry between 2006 and 2014. The main findings were as follows: 1) The use of coronary angiography increased (from 77 to $90 \%)$; 2) There was a significant decrease in median time to coronary angiography; 3 ) There was an increase in patients undergoing early invasive strategy; 4) A higher GRACE risk score was associated with a delayed invasive strategy; 5) No difference was observed in mortality, reinfarction and bleeding event at 30-day follow-up between early and delayed invasive strategy after adjustment for confounding factors.

The increased use of coronary angiography, decrease in the median time to coronary angiography and increase of patients undergoing early invasive strategy can probably be explained by the ESC guideline recommendations. This observation is in line with a similar report from the Swedish SWEDEHEART registry [13]. However, contrary to what might be expected based on these recommendations, patients with a higher baseline risk profile as indicated by the GRACE risk score less frequently underwent an early invasive strategy. This inverse relationship between risk profile and the use of invasive treatment, the treatment-risk paradox, has been described previously [13, 14]. The explanation for this treatmentparadox is likely multifactorial [14]. Treating physicians may fail to recognise high-risk clinical features or to properly integrate them into overall risk stratification. Moreover, physicians may be hesitant to recommend or perform invasive procedures for patients at high risk for treatment complications. 'Therapeutic nihilism' (belief that treatment might be ineffective in patients with poor outcome) may also play a role. To be noted, factors that are not routinely captured in risk scores or studies, such as functional status, patient's preference and frailty, do influence treatment decisions in everyday practice.

Finally, even though higher-risk patients were treated with a delayed invasive strategy, no difference was observed in clinical outcomes between an early invasive strategy and a delayed invasive strategy. A subgroup analysis showed that this finding was consistent in patients with a GRACE score above 140. Although these results have to be interpreted in the light of the limitations of a non-randomised comparison, the results are in line with previous Dutch randomised studies regarding timing of coronary angiography/intervention in NSTE-ACS patients [15, 16]. In addition to the above-mentioned availability of catheterisation laboratories in the majority of Dutch cardiology departments, this important finding might be explained by the correct identification of true high-risk patients by the treating physician. In the recently published Danish VERDICT trial, NSTEACS patients were randomised to coronary angiography within 12 hours or within 48 to 72 hours [17]. Although no differences in outcomes were observed, there was a benefit of coronary angiography within 12 hours with regard to long-term outcomes in patients with a GRACE risk score above 140. The question then arises whether high-risk NSTE-ACS patients presenting to a cardiology department without coronary angiography capabilities should be transferred to a PCI-capable centre. We believe that a Dutch randomised trial investigating these treatment strategies in high-risk patients is needed, because the clinical and logistical (ambulance and catheterisation facilities/laboratories) implications of inter-facility transfer are significant.

Open Access This article is distributed under the terms of the Creative Commons Attribution 4.0 International License (http://creativecommons.org/licenses/by/4.0/), which permits unrestricted use, distribution, and reproduction in any medium, provided you give appropriate credit to the original author(s) and the source, provide a link to the Creative Commons license, and indicate if changes were made.

\section{References}

1. Davies MJ. The pathophysiology of acute coronary syndromes. Heart. 2000;83:361-6.

2. Steg PG, James SK, Atar D, et al. ESC guidelines for the management of acute myocardial infarction in patients presenting with ST-segment elevation. Eur Heart J. 2012;33:2569-619.

3. Keeley EC, Bour JA, Grines CL. Primary angioplasty versus intravenous thrombolytic therapy for acute myocardial infarction: a quantitative review of 23 randomised trials. Lancet. 2003;36:13-20.

4. Damman P, Hirsch A, Windhausen F, Tijssen JG, de Winter RJ, ICTUS Investigators. 5-year clinical outcomes in the ICTUS (Invasiveversus Conservative Treatmentin Unstable coronary Syndromes) trial a randomized comparison of an early invasive versus selective invasive management in patients with non-ST-segment elevation acute coronary syndrome. JAm Coll Cardiol. 2010;55:858-64.

5. Fox KA, Clayton TC, Damman P, et al. Long-term outcome of a routine versus selective invasive strategy in patients with non-ST-segment elevation acute coronary syndrome ameta-analysis of individual patient data. JAm CollCardiol. 2010;55:2435-45.

6. Roffi M, Patrono C, Collet JP, et al. 2015 ESC guidelines for the management of acute coronary syndromes in patients presenting without persistent ST-segment elevation: Task Force for the Management of Acute Coronary Syndromes in Patients Presenting without Persistent ST-Segment Elevation of the European Society of Cardiology (ESC). Eur HeartJ.2016;37:267-315.

7. Riezebos RK, Ronner E, Ter Bals E, et al. Immediate versus deferred coronary angioplasty in non-ST-segment elevation acute coronary syndromes. Heart. 2009;95:807-12.

8. Thiele H, Rach J, Klein N, et al. Optimal timing of invasive angiography in stable non-ST-elevation myocardial infarction: the Leipzig Immediate versus early and late Per- 
cutaneouS coronary Intervention triAl in NSTEMI (LIPSIANSTEMITrial). Eur HeartJ. 2012;33:2035-43.

9. MontalescotG,Cayla G,ColletJP, etal. Immediatevs delayed intervention for acute coronary syndromes: a randomized clinical trial. JAMA. 2009;302:947-54.

10. Jobs A, MehtaSR, Montalescot G, et al. Optimal timing of an invasive strategy in patients with non-ST-elevation acute coronary syndrome: a meta-analysis of randomised trials. Lancet. 2017;390(10096):737-46.

11. Damman P, van 't Hof AW, Ten Berg JM, et al. 2015 ESC guidelines for the management of acute coronary syndromes in patients presenting without persistent STsegment elevation: comments from the Dutch ACS working group. Neth HeartJ. 2017;25:181-5.

12. Badings EA, Hermanides RS, van der Sluis A, et al. Use, timing and outcome of coronary angiography in patients with high risk non-ST-segment elevation acute coronary syndrome in daily clinical practice-insights from a 'real world' prospective registry. Neth Heart J. 2019; https:// doi. org/10.1007/s12471-018-1212-3.

13. Damman P, Jernberg T, Lindahl B, et al. Invasive strategies and outcomes for non-ST-segment elevation acute coro- nary syndromes: a twelve-year experience from SWEDEHEART. EuroIntervention. 2016;12:1108-16.

14. Canadian Acute Coronary Syndromes 1 and 2 Registry Investigators, Yan AT, Yan RT, Tan M, et al. Management patterns in relation to risk stratification among patients with non-ST elevation acute coronary syndromes. Arch Intern Med. 2007;167:1009-16.

15. Oosterwerff EF, Fagel ND, Slagboom T, et al. Impact of percutaneous coronary intervention timing on 5-year outcome in patients with non-ST-segment elevation acute coronary syndromes. The 'wait a day' approach might be safer. Neth Heart J. 2016;24:173-80.

16. Badings EA, The SH, Dambrink JH, et al. Early or late intervention in high-risk non-ST-elevation acute coronary syndromes: results of the ELISA-3 trial. EuroIntervention. 2013;9:54-61.

17. Koefoed KF, et al. Early versus standard care invasive examination and treatment of patients with non-ST-segment elevation acute coronary syndrome: the VERDICT (very EaRly vs deferred invasive evaluation using computerized Tomography)—randomized controlled trial. Circulation. 2018 (in print). 